\title{
ATOMIC ABSORPTION SPECTROPHOTOMETER - A VERSATILE TOOL FOR THE ESTIMATION OF NICKEL CONTENT IN DRONEDARONE
}

\author{
VASAVI DEVI DASARI ${ }^{1 *}$, SWARNALATHA DUGASANI ${ }^{2}$ VENKATASUBBA REDDY GOPIREDDY $^{3}$
}

${ }^{1}$ JNTUA, Ananthapuramu, Andhra Pradesh, India. ${ }^{2}$ Department of Pharmaceutical Sciences, Annamacharya College of Pharmacy, Rajampeta, Andhra Pradesh, India. ${ }^{3}$ Department of Chemistry, Jawaharlal Nehru Technological University Anantapur College of Engineering, Pulivendula, Andhra Pradesh, India. Email: dvas.reddy@gmail.com

Received: 04 May 2019, Revised and Accepted: 25 June 2019

ABSTRACT

Objective: The present investigation is to develop a validated analytical method for the determination of nickel content in dronedarone hydrochloride bulk drug by atomic absorption spectrophotometer (AAS).

Methods: Samples were analyzed after a preparation of sample solution by dissolving in suitable diluents of nitric acid and perchloric acid. In the present method, AAS with $0.2 \mathrm{~nm}$ slit width, nickel hollow cathode lamp with a wavelength of $232 \mathrm{~nm}$ has been employed.

Results: The system suitability parameters were performed to assess the system performance. The limit of detection and limit of quantification (LOQ) were found to be $0.051 \mathrm{ppm}$ and $0.15 \mathrm{ppm}$, respectively. The percentage recovery at LOQ, 50\%, 100\%, and $150 \%$ levels of nickel in dronedarone was found to be $95.55,109.33,96$, and 97.55 , respectively.

Conclusion: With the developed method, the nickel content in dronedarone bulk sample was found to be $3.0 \mathrm{ppm}$.

Keywords: Dronedarone, Nickel, Atomic absorption spectrophotometer, Validation.

(C) 2019 The Authors. Published by Innovare Academic Sciences Pvt Ltd. This is an open access article under the CC BY license (http://creativecommons. org/licenses/by/4. 0/) DOI: http://dx.doi.org/10.22159/ajpcr.2019.v12i8.33921

\section{INTRODUCTION}

Dronedarone is a Class III antiarrhythmic drug recently approved by the US Food and Drug Administration in 2009 for the treatment of nonpermanent atrial fibrillation and atrial flutter [1]. The chemical name is $\mathrm{N}$-[2-butyl-3[4-[3-(dibutylamino) propoxy]benzoyl]-1-benzofuran5-yl] methanesulfonamide hydrochloride according to IUPAC. Its molecular formulae are $\mathrm{C}_{31} \mathrm{H}_{44} \mathrm{~N}_{2} \mathrm{O}_{5} \mathrm{~S}$. $\mathrm{HCl}$ with a molecular weight of $593.22 \mathrm{~g} / \mathrm{mol}$ [2]. Chemically, it is a benzofuran derivative containing heterocyclic compound which is a structural analog of amiodarone. DRO reduces the toxic effects in amiodarone by replacing the iodine group with a methanesulfonyl group [3]. Due to reduced lipophilicity, it has lower toxicity and superior pharmacokinetic characteristics than the amiodarone belonging to the same Class III antiarrhythmic drug [4]. $\mathrm{DRO}$ is crystalline in nature with a melting point of $149-153^{\circ} \mathrm{C}$ [5], with white to practically white, non-hygroscopic fine powder. It is a new active substance, and there is no official pharmacopoeial procedure available [6]. Literature overviews confess that drug was estimated by different analytical strategies such as spectrophotometric [7], highperformance liquid chromatography [8-17], and liquid chromatography mass spectrometry $[18,19]$ in bulkdrugs and formulation of dronedarone. From the review, it was found that there were no reported methods for the estimation of elemental impurity, i.e., nickel in dronedarone. Impurity profiling of pharmaceutical products was an extensive scope of concern. Rigid modulations are leaving behind for their effective use. Regarding the various regulatory guidelines, impurities are majorly organic or inorganic in nature (USP, ICH). To a great extent, we know about organic impurities, during the time inorganic impurities are procuring importance at recent times. The inorganic impurities, i.e., metal contamination, enter the standard reference materials and intermediates through crude materials, impetuses, reagents, solvents, and different supplies utilized for blend and for synthesis, This metal ions invaded possess the capability to decompose the materials of interest, which may sometimes prompt to potential noxious impacts, further to self-toxicity. Hence, it is necessary to monitor metal ion contents in the standard reference material of drugs [20,21]. Various analytical strategies were utilized for the determination of inorganic metal impurities including titration, ion-exchange chromatography, capillary electrophoresis, and spectroscopic techniques such as flame photometry, fluorimetry, atomic absorption spectroscopy, and inductively coupled plasma. The titration strategies are not exact, whereas ion-exchange chromatography and capillary electrophoresis stabilization is a time-taking procedure and sensitivities are low when contrasted with atomic absorption spectrophotometer (AAS). For the above reasons, AAS has become a tool of choice for estimating metals. The present study was to carry out method development and validated using atomic absorption spectrophotometry to determine nickel content in dronedarone.

EXPERIMENTAL

Chemicals and reagents

Nickel standard from Merck, nitric acid and perchloric acid from SDFCL chemicals, Milli-Q water, and API as a gift sample were used in the study.

\section{Instrumentation and operating conditions}

AAS of model AA-6300 (Shimadzu) equipped with fully integrated atomizers of Shimadzu make was used for the analysis. The system was regulated from an interfaced PC running Wizard software. Atomic absorption measurements were carried out at $232 \mathrm{~nm}$ analysis wavelength, using nickel hollow cathode lamp, lamp current - $7 \mathrm{~mA}$, slit width $-0.2 \mathrm{~mm}$, burner height $-7 \mathrm{~mm}$, oxidant flow - $15 \mathrm{~L} / \mathrm{min}$, acetylene flow $-1.6 \mathrm{~L} / \mathrm{min}$ lamp mode - BGC-D2, pre-spray time - $5.0 \mathrm{~s}$, integration time - $5 \mathrm{~s}$, and recommended flame - air acetylene.

Preparation of solutions

Preparation of nickel standard stock solution (solution A)

The $10 \mathrm{~mL}$ of $1000 \mathrm{mg} / \mathrm{L}$ concentrated nickel standard solution is taken into a $100 \mathrm{~mL}$ volumetric flask and dilute up to mark with Milli-Q 
water which contains $100 \mathrm{mg} / \mathrm{L}$ of nickel. Prepare $5 \mathrm{mg} / \mathrm{L}$ of nickel by transferring $5 \mathrm{~mL}$ of above solution into a $100 \mathrm{~mL}$ volumetric flask and make up to volume with Milli- $Q$ water.

\section{Preparation of blank solution}

Take $10 \mathrm{~mL}$ of concentrated nitric acid and $10 \mathrm{~mL}$ of perchloric acid to a $100 \mathrm{~mL}$ beaker. Heat on a hot plate until the volume is reduced to about $6 \mathrm{~mL}$ to $7 \mathrm{~mL}$ and white fumes are evolved. Cool the solution and transfer to $10 \mathrm{~mL}$ volumetric flask and dilute up to mark with Milli-Q water

\section{Preparation of sample solution}

Weighed accurately $1.0023 \mathrm{~g}$ of sample and transfer into $100 \mathrm{~mL}$ beaker. To this add $10 \mathrm{~mL}$ of concentrated nitric acid and $10 \mathrm{~mL}$ of perchloric acid. Heat on hot plate until the volume is reduced to about $6 \mathrm{~mL}$ to $7 \mathrm{~mL}$ and white fumes are evolved. Cool the solution and transfer to $10 \mathrm{~mL}$ of clean and dry volumetric flask and dilute up to mark with Milli-Q water.

\section{Preparation of $L O Q$ standard solution}

The limit of quantification (LOQ) standard solutions were prepared by taking $0.77 \mathrm{ml}$ of the above solution $\mathrm{A}$ to a $25 \mathrm{ml}$ volumetric flask and dilute up to volume with Milli- $Q$ water which contains $0.154 \mathrm{ppm}$ of nickel. This solution has been used for the determination of precision at LOQ level.

\section{ESTABLISHMENT OF THE METHOD}

\section{Selection of wavelength}

The wavelength for the selected metal is taken as a default by the AAS instrument. The wavelength which is used in the determination of metal is given in Fig. 1. The prepared sample was aspirated in the Shimadzu AA-6300, AAS instrument. Here, a light shaft from a nickel hollow cathode lamp is gone through the sample which is atomized in a flame into a monochromator and onto a detector that estimates the amount of absorbed light.

\section{Validation of the established method}

The validation of the systematic method for quantitative assurance of nickel was performed as per the USP guidelines by evaluating linearity, specificity, detection limit, quantitation limit, accuracy, precision at LOQ level, and method precision. The goal of analytical estimation is to get steady, solid, and exact information. Approved analytical strategies assume a noteworthy job in accomplishing this objective. The outcomes from strategy approval can be utilized to pass judgment on the quality, unwavering quality, and consistency of logical outcomes, which is an indispensable piece of any great analytical practice.

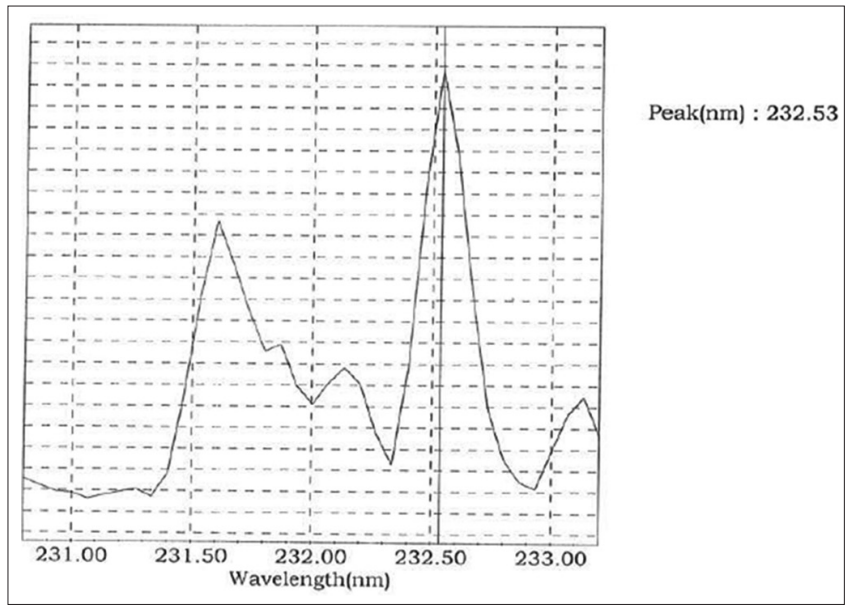

Fig. 1: Wavelength selection

\section{System suitability}

To guarantee the execution of the framework, the system suitability is measured, which is an essential piece of analytical systems. The system suitability test was carried out to validate whether nickel content can be identified by injecting system suitability solution. The standard working solution with a concentration of $0.5 \mathrm{mg} / \mathrm{L}, 1 \mathrm{mg} / \mathrm{L}, 1.5 \mathrm{mg} / \mathrm{L}$, $2 \mathrm{mg} / \mathrm{L}$, and $2.5 \mathrm{mg} / \mathrm{L}$ was prepared using solution $\mathrm{A}$ and aspired into the flame of AAS.

\section{Specificity}

Specificity is the capacity to evaluate the analyte in the test with presents of startling different components which meddle the consequences of analyte in test. One hundred percent nickel standard solution is prepared by taking $5 \mathrm{~mL}$ of solution A into a $25 \mathrm{~mL}$ volumetric flask and make up to volume with Milli- $\mathrm{Q}$ water The obtained solution with a concentration of $1 \mathrm{mg} / \mathrm{L}$ of nickel solution is used as $100 \%$ standard solution. The blank and sample solutions which are prepared have been aspirated into the flame of AAS.

\section{Linearity}

Linearity is assessed through graphical portrayal of the deliberate absorbance and concentration of the solution. The calibration plot was constructed with blank samples and five different concentrations from $0.5 \mathrm{mg} / \mathrm{L}$ to $2.5 \mathrm{mg} / \mathrm{L}$. From the linear solutions, correlation coefficient, Y-intercept, slope was calculated.

The execution of an instrument or an analytical technique is evaluated by determining detection limit and quantitation limit.

\section{Detection limit}

The detection limit is the most reduced measure of analyte in a sample that can be distinguished, yet not really quantitated, under the expressed experimental conditions. In this manner, limit tests only substantiate that the measure of analyte is above or underneath a specific level. As far as possible, it is normally expressed as the concentration of analyte (\% or ppb) in the sample.

\section{Quantitation limit}

It is the most reduced measure of analyte in a sample that can be resolved with adequate precision and accuracy under the expressed experimental conditions. As far as possible, it is expressed as the concentration of analyte (e.g., \% or ppb) which can be quantitatively measured in the sample.

\section{Precision at LOQ leve}

The prepared LOQ sample was taken and used in the precision studies. Precision was reported as percentage relative standard deviation (\% RSD) by aspirating the nickel standard for 6 times. The results were presented in a table, which are within the range of acceptance criteria $(\% \mathrm{RSD} \leq 5)$

\section{Accuracy}

Accuracy is the closeness of the test outcomes gotten by the technique to the genuine esteem value which was obtained by spiking $50 \%$, $100 \%$, and $150 \%$ of dronedarone working standard concentrations in triplicates, and accuracy/recovery was shown in \% RSD and its percentage recovery should be in between $80 \%$ and $120 \%$.

\section{Method precision}

The analytical procedure should be surveyed by estimating the concentrations of six autonomously prepared sample solutions at $100 \%$ of the assay test concentration

\section{Batch analysis}

Weigh precisely $1.0033 \mathrm{~g}$ of sample and transfer into $100 \mathrm{ml}$ of beaker. Add $10 \mathrm{ml}$ of concentrated nitric acid and $10 \mathrm{ml}$ of perchloric acid. Heat on hot plate until the volume is reduced to about $6 \mathrm{ml}$ to $7 \mathrm{ml}$ and white fumes are evolved. Cool the solution and transfer to $10 \mathrm{ml}$ of clean and dry volumetric flask and dilute up to mark with Milli-Q water. 


\section{DISCUSSION OF THE RESULTS}

Using the above sophisticated AAS method, samples were analyzed using the wavelength $232.53 \mathrm{~nm}$ which was default selected by the AAS (Fig. 1). The nickel content in the given dronedarone hydrochloride was found to be $3.0 \mathrm{ppm}$. The developed technique was approved according to USP rules, and the linearity was within the scope of $0.5 \mathrm{mg} / \mathrm{L}$ to $2.5 \mathrm{mg} / \mathrm{L}$ and is shown in Fig. 2 and Table 1.

The detection limit and LOQ values were established from linearity and were found to be $0.050698 \mathrm{ppm}$ and $0.15363 \mathrm{ppm}$, respectively. The \% RSD for absorbance of nickel standard solution (LOQ solution) six replicates was found to be 6.237 . The method was specific, and the absorbance obtained with the blank solution was below the absorbance obtained for $100 \%$ standard solution and is shown in Table 2 . The

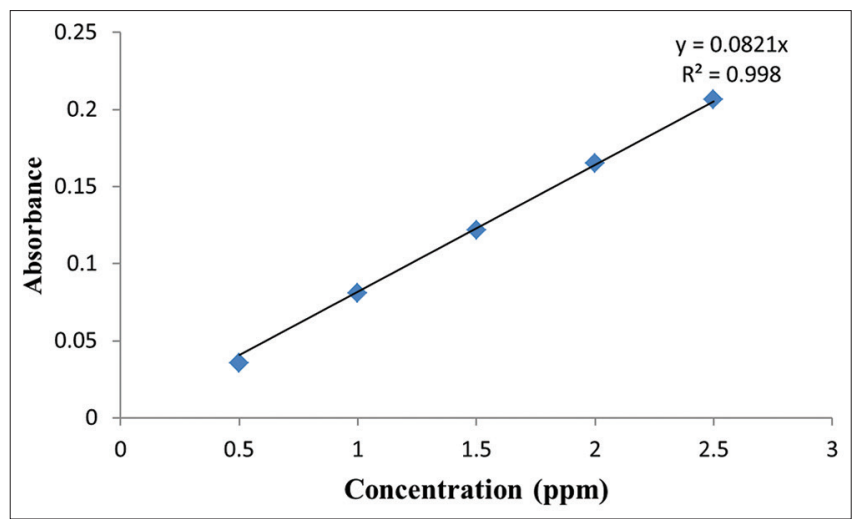

Fig. 2: Calibration graph repeatability of the method was determined by injection of six preparations, and the \% RSD was found to be 1.52608 . The percentage recovery was determined at LOQ, 50\%, 100\%, and $150 \%$ levels, and their percentage recovery and \% RSD are represented in Table 2 . The percentage recovery by performing accuracy was within the acceptable limit and is represented in the table.

\section{CONCLUSIONS}

The state-of-the-art describes the development and validation of a method for the examination of nickel in dronedarone using flame atomic absorption spectroscopy. The allowed nickel content is up to $20 \mathrm{ppm}$ as per USP-NF 40 . The sample which is analyzed using the method developed is $3.0 \mathrm{ppm}$, so the nickel content in the taken sample is inacceptable range. Hence, the method can be successfully used for the quantification of nickel in dronedarone drug substance. The validation results are displayed and sorted out in tables with the end goal to give a simple overview of the method execution. The validation information demonstrates that the present developed technique has met al. acceptance criteria.

\section{AUTHOR' S CONTRIBUTIONS}

Concept - Vasavi; Design - Subba Reddy, Vasavi, Swarnalatha; Supervision - Subba Reddy, Swarnalatha; Materials - Vasavi; Data Collection and/or Processing - Vasavi; Analysis and/or Interpretation - Vasavi, Subba Reddy, Swarnalatha; Literature Search - Vasavi, Subba Reddy, Swarnalatha; Writing - Vasavi; Critical Reviews - Vasavi, Subbareddy, Swarnalatha.

\section{CONFLICTS OF INTEREST}

The authors report no conflicts of interest.

Table 1: Calibration curve

\begin{tabular}{llc}
\hline S.No. & Concentration (PPM) & $\begin{array}{c}\text { Absorbance } \\
\text { coefficient }\end{array}$ \\
\hline 1 & Standard 1 (0.5 mg/L) & 0.0355 \\
2 & Standard 2 (1.0 mg/L) & 0.0811 \\
3 & Standard 3 (1.5 mg/L) & 0.1221 \\
4 & Standard 4 (2.0 mg/L) & 0.1651 \\
5 & Standard 5 (2.5 mg/L) & 0.2066 \\
\hline
\end{tabular}

Table 2: Summary report

\begin{tabular}{|c|c|c|c|c|}
\hline \multicolumn{5}{|c|}{ Summary report } \\
\hline S.No. & Parameter & Acceptance criteria & Observation & Result \\
\hline 1 & System suitability & Correlation coefficient should be NLT 0.99 & 0.996 & Pass \\
\hline 2 & Specificity & Any absorbance obtained with the blank solution should be $\leq 5 \%$ of & Meeting the acceptance criteria & Pass \\
\hline 3 & Linearity & $\begin{array}{l}\text { the absorbance obtained for } 100 \% \text { standard solution } \\
\text { Correlation coefficient should be NLT } 0.99\end{array}$ & 0.998 & Pass \\
\hline \multirow[t]{3}{*}{4} & \multirow{3}{*}{$\begin{array}{l}\text { LOD and LOQ } \\
\text { precision at LOQ }\end{array}$} & LOD and $\mathrm{OOO}$ values established from linearity The & LOD - $0.05 \mathrm{ppm}$ and LOQ - $0.15 \mathrm{ppm}$ & Pass \\
\hline & & percentage RSD for absorbance of Nickel standard & $6.237 \%$ & Pass \\
\hline & & solution (LOQ solution) six replicates should be NMT & At LOQ - 95.55\% & Pass \\
\hline \multirow[t]{7}{*}{5} & \multirow[t]{7}{*}{ Accuracy/recovery } & $\begin{array}{l}15.0 \\
\text { The percentage recovery at each level should be in between }\end{array}$ & At $50 \%-109.33 \%$ & Pass \\
\hline & & $80 \%-120 \%$ and for LOQ level should be in between $70 \%-130 \%$ & At $100 \%-96.00 \%$ & \\
\hline & & The percentage RSD at each Level 3 preparation should be NMT 5.0 & At $150 \%-97.55 \%$ & \\
\hline & & & At LOQ - $4.03 \%$ & \\
\hline & & & At $50 \%-4.22 \%$ & \\
\hline & & & At $100 \%-1.04 \%$ & \\
\hline & & & At $150 \%-0.3965 \%$ & \\
\hline 6 & Method precision & $\begin{array}{l}\text { The percentage RSD for nickel content six preparations should be } \\
\text { NMT } 15.0\end{array}$ & 1.526 & Pass \\
\hline \multirow[t]{2}{*}{7} & Batch analysis & Obtained results are reported & $3.0 \mathrm{ppm}$ & Pass \\
\hline & & The Nickel content should be NMT 20 ppm & & \\
\hline
\end{tabular}

LOD: Limit of detection, LOQ: Limit of quantification, NLT: Not less than, NMT: Not more than, RSD: Relative standard deviation 
GRAPHICAL ABSTRACT

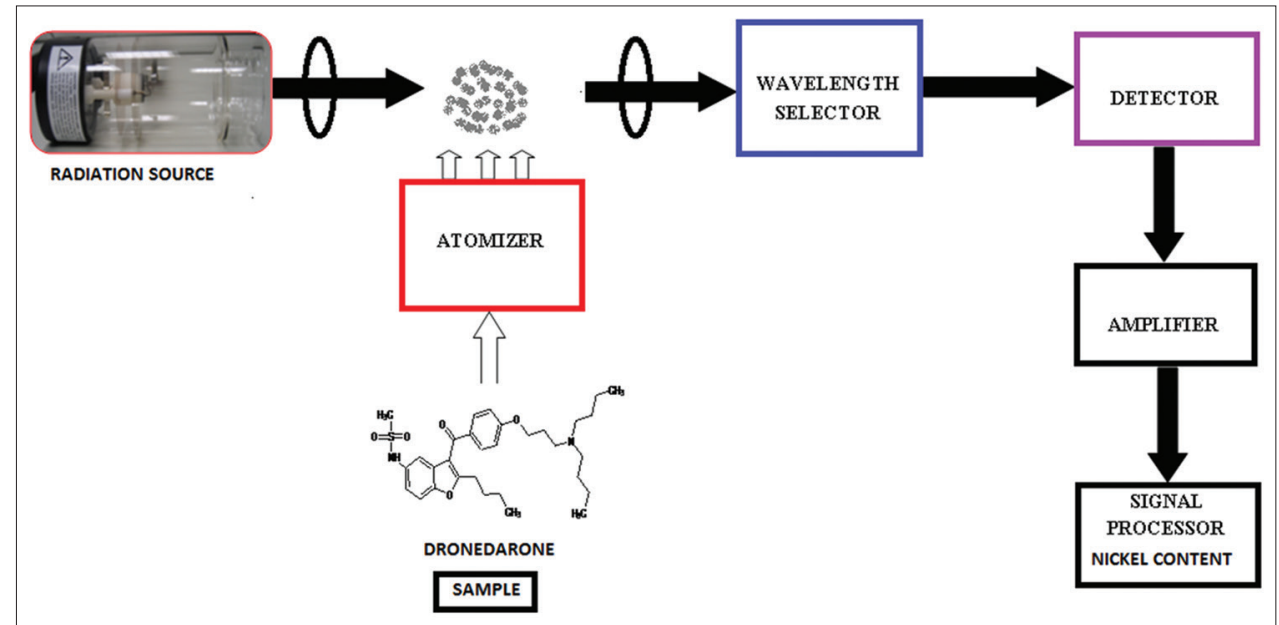

\section{REFERENCES}

1. Food and Drug Administration. Center for Drug Evaluation and Research, Clinical Pharmacology and Biopharmaceutics Reviews. Available from:. [Last accessed on 2018

2. Ha E, Lee Y, Kim M. Solubility of dronedarone hydrochloride in six pure solvents at the range of 298.15 to 323.15K. J Mol Liq 2016;216:360-3.

3. Assessment Report for Multaq. Evaluation of Medicines for Human Use, European Medicines Agency, Procedure No. EMEA/H/C/001043; 2009. Available from: [Last accessed on 2018

4. Penugonda N, Mohmand-BorkowskiA,Burke JF.Dronedarone for atrial fibrillation: How does it compare with amiodarone? Cleve Clin J Med 2011;78:179-85.

5. Iram F, Ali S, Ahmad A, Khan S, Husain A. A review on dronedarone: Pharmacological, pharmacodynamic and pharmacokinetic profile. J Acute Dis 2016;5:102-8.

6. El Sheikh R, Gouda AA, Mostafa AH, Din SE. Development of efficient cloud point extraction method for preconcenration and spectrophotometric determination of nickel in water samples using 2-(benzothiazolylzao)orcinol. Int J Pharm Pharm Sci 2015;7:176-84.

7. Elsheikh R, Gouda AA, Elsayed HA, Alamin EM. Cloud point extraction, preconcenration and spectrophotometric determination of cobalt in water samples. Int J Pharm Pharm Sci 2015;7:213-21

8. Jain PS, Bari PR, Girase DS, Kadtan DB, Ishi PL, Shinkar DA. Area under curve method development and validation for estimation of dronedarone in bulk and tablet dosage form. J Pharm Bio Sci 2013;2:44-7.

9. Jadhav D, Konam K. Development and validation of a RP-HPLC method for determination of dronedarone in bulk and pharmaceutical formulation. Int J Pharm Biol Sci 2014;4:179-85

10. Bhatt KK. Development of a validated stability-indicating RP-HPLC method for dronedarone hydrochloride in pharmaceutical formulation. J Anal Bioanal Tech 2013;4:161

11. Landge S, Jadhav S, Nimbalkara K, Mali A, Mathad V. Stability indicating RP-HPLC method for the determination of dronedarone hydrochloride and its potential process-related impurities in bulk drug and pharmaceutical dosage form. Am J Anal Chem 2013;4:323-35.

12. Nahid L, Pavani H. Development and validation of HPLC method for simultaneous determination of ranolazine and dronedarone in bulk and pharmaceutical dosage forms. Indian J Res Pharm Biotechnol 2014;2:1525-28

13. Dabhi B, Jebaliya H, Jadeja Y, Patel M, Shah A, Karia D. Fast Stability indicating UPLC method for quantitative analysis of dronedarone in pharmaceutical dosage form: Force degradation study. Chromatography 2014;2014:1-7.

14. Chavakula R, Chintala R, Tadanki B. Forced degradation study on dronedarone and application of validated stability-indicating HPLCUV method in stability testing of dronedarone tablets. Der Pharm Chem 2013;5:189-95.

15. Akhtar J, Patel R. RP-HPLC method development and validation of dronedarone $\mathrm{HCl}$ in its pure form and tablet dosage form. J Chem Pharm Res 2012;4:2173-9

16. Tondepu N, Sait S, Surendranath K, Kaja R, Kumar S. A stability indicating HPLC method for dronedarone in bulk drugs and pharmaceutical dosage forms. Am J Anal Chem 2012;03:544-51.

17. Rao KN, Ganapaty S, Rao AL. A simple and sensitive RP-HPLC method for estimation of dronedarone in bulk and tablet dosage forms. Asian J Res Chem 2012;5:1381-4.

18. Peng-fei J, Xiao-li L. HPLC determination of dronedarone hydrochloride tablets and its related substances. Chin J Pharm Anal 2013;33:450-3

19. Chadha R, Bali A, Bansal G. Identification and characterization of stress degradation products of dronedarone hydrochloride employing LC-UV/PDA, LC-MS/TOF and MS n studies. J Pharm Biomed Anal 2016;118:139-48.

20. Xie C, Yang S, Zhong D, Dai X, Chen X. Simultaneous determination of dronedarone and its active metabolite debutyldronedarone in human plasma by liquid chromatography-tandem mass spectrometry: Application to a pharmacokinetic study. J Chromatogr B Analyt Technol Biomed Life Sci 2011;879:3071-5.

21. European Medicines Agency. Guideline on the Specification Limits for Residues of Metal Catalysts or Metal Reagents European Medicines Agency; 2018.

22. Stoving C, Jensen H, Gammelgaard B, Sturup S. Development and validation of an ICP-OES method for quantitation of elemental impurities in tablets according to coming US pharmacopeia chapters. J Pharm Biomed Anal 2013;84:209-14. 